\title{
Synthesis and characterization of nanostructured molybdenum \& tungsten carbide materials, and study of diffusion model
}

\author{
Leroy Covington, Kamalesh Munirathinam, Akand W. Islam*, Kenneth L. Roberts \\ Department of Chemical Engineering, North Carolina A\&T State University, 1601 E Market St, NC 27411, USA \\ * Corresponding author: e-mail: awislam@crimson.ua.edu
}

\begin{abstract}
Powders of two molybdenum carbides $\left(\mathrm{Mo}_{2} \mathrm{C}\right.$ and $\left.\mathrm{MoC}_{1-\mathrm{x}}\right)$ and tungsten carbide (WC) were prepared by means of temperature programmed reaction (TPR) method. $\mathrm{Mo}_{2} \mathrm{C}$ and $\mathrm{MoC}_{1-\mathrm{x}}$ were synthesized by reacting $\mathrm{MoO}_{3}$ with a preselected molar ratio of methane/hydrogen and carbon monoxide/hydrogen gas mixtures respectively. WC was prepared using tungsten oxide $\left(\mathrm{WO}_{3}\right)$ and a methane/hydrogen gas mixture. These carbides were ultrasonically dispersed in de-ionized water. Samples were characterized using room temperature $\mathrm{x}$-ray diffraction and scanning microscopy. A kinetic diffusion model is also studied to determine diffusivities in solids where the diffusing species desorbs or reacts at the external surfaces, and where the diffusivity does not vary appreciably with concentrations. The method involves measuring the flux of the diffusive species into the solid under the influence of a temperature program.
\end{abstract}

Keywords: molybdenum carbide, tungsten carbide, temperature programmed reaction, sonochemistry, nanostructure.

\section{INTRODUCTION}

The carbides of molybdenum and tungsten constitute a diverse class of materials with many technological applications. Because of their great strength and durability, they have been traditionally used at extreme conditions of temperature and pressure, for example, in rocket nozzles and drill bits. Their hardness has given them applications in cutting tools, golf shoe spikes, and snow tires ${ }^{1-3}$. These compounds have shown great potential for use as a commercial hydrodenitrogenation ${ }^{4,5}$ catalyst. Nanostructured carbide materials can help the microelectronics industry by providing the manufacturers with nanocrystalline starting materials, ultra-high purity materials, materials with better thermal conductivity, and longer-lasting, durable interconnections (connections between various components in the microprocessors).

Nanocrystalline $\mathrm{Mo}_{2} \mathrm{C}$ can be synthesized using sodium metal in the co-reduction reaction of molybdenum pentachloride $\left(\mathrm{MoCl}_{5}\right)$ and carbon tetrabromide $\left(\mathrm{CBr}_{4}\right)$ in a benzene reaction medium at $350^{\circ} \mathrm{C}$ for 12 h (hours) ${ }^{6}$. Hyeon et al., ${ }^{7}$ synthesized nanostructured molybdenum carbide from the ultrasonic irradiation of molybdenum hexacarbonyl in hexadecane. One of synthesis methods of Tungsten Carbide is by reaction between tungsten powder and soot $^{8}$. Weimer ${ }^{9}$ reported a number of processes for the production of WC. A simple, inexpensive, and versatile route for the synthesis of metal carbides $\left(\mathrm{Mo}_{2} \mathrm{C}\right.$ and $\left.\mathrm{WC}\right)$ nanoparticles were set up by Giordano and her co-authors ${ }^{10}$. Patel and Subrahmanyam ${ }^{11}$ synthesized $\mathrm{Mo}_{2} \mathrm{C}$ of less than $10 \mathrm{~nm}$ by solution route. Keller et al. ${ }^{12}$, obtained a new medium specific surface area one-dimensional WC nanostructure by the shape memory synthesis method, in which they maintained the macrostructural features of a carbonaceous 1-D (dimensional) preformed template during the carburization of tungsten-oxide and determined the resulting carbide morphology. Singh ${ }^{13}$ developed thermochemical route for the synthesis of WC nanoparticles. Yamada $^{14}$ presented a fast formation mechanism of WC from a tungsten-acetylene black powder mixture by an oblique shock wave technique. Kurishita et al., ${ }^{15}$ presented a contemporary status of the development of nanostructured refractory transition metals of $\mathrm{W}$ and Mo emphasizing the effects of nano-structures upon the mitigation embrittlement by high ductile-to-brittle transition temperature (low temperature embrittlement) and by irradiation (radiation embrittlement). There are also many other recent investigations that have been carried out on WC synthesis ${ }^{16-18}$.

In this research temperature programmed reaction $(\mathrm{TPR})^{19}$ method was applied for the synthesis of Molybdenum and Tungsten carbides. TPR is one of the thermoanalytical techniques for the characterization of chemical interactions between gaseous reactants and solid substances. This is a transient response technique in which some characteristic property of a solid sample is related to its temperature in a process of programmed heating. Exchange of matter and/or energy between the sample and its surroundings provide means as a function of temperature, the thermogram, reflects the nature of the system under study and the experimental conditions. Thermal analysis is used as a tool for quantitative analysis for the evaluation of the influence of different factors on the reactivity. The comprehensive review on this technique is illustrated by several investigators ${ }^{20-25}$. This method of preparation consists in treating the temperature in a uniform manner. The precursor can be an oxide, sulfide, nitride, or other compound while the reactive gas can be a mixture of a hydrocarbon and hydrogen for carbides ${ }^{1}$. Sonochemistry principles were used to propose a mechanism to disperse the as-prepared particles followed by TPR. Finally XRD, elemental analysis, and SEM were employed to characterize the particles.

\section{EXPERIMENTAL METHODS AND MATERIALS}

Powders of two molybdenum carbides $\left(\mathrm{Mo}_{2} \mathrm{C}\right.$ and $\left.\mathrm{MoC}\right)$ were synthesized by reacting $\mathrm{MoO}_{3}$ with pre-selected molar ratios of $\mathrm{CH}_{4}$ (Air Products and Chemicals Inc., $\mathrm{CP}$ grade) / $\mathrm{H}_{2}$ and $\mathrm{CO}$ (National Welders, CP Grade)/ $\mathrm{H}_{2}$ gas mixtures respectively. WC was produced by 


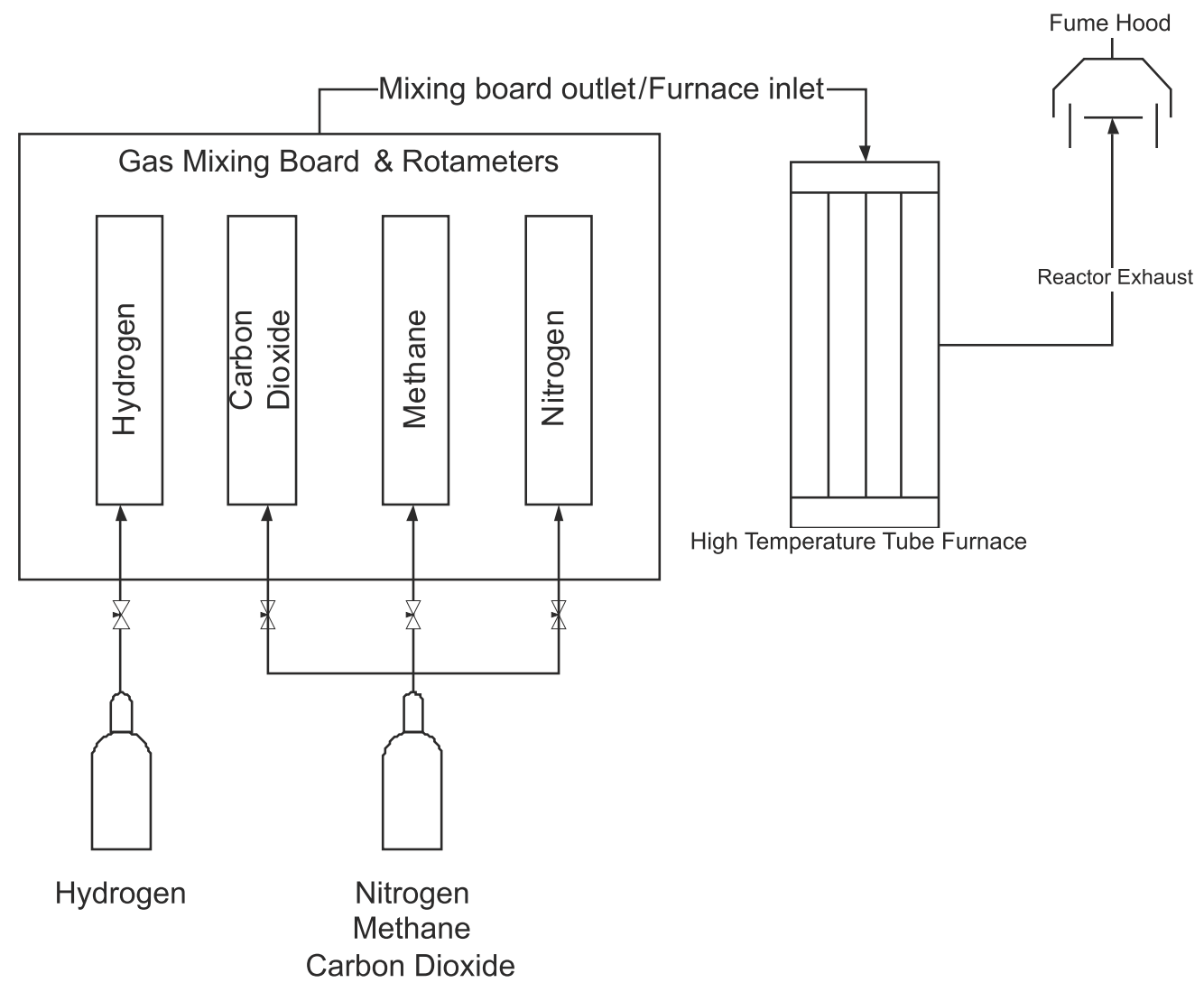

Figure 1. Porous Interstitial Compound Synthesis Apparatus

reacting $\mathrm{WO}_{3}$ in a $\mathrm{CH}_{4} / \mathrm{H}_{2}$ environment. The reaction gases were mixed and monitored through a mixing board that contained needle valves and rotameters (Omega Engineering, Inc). Approximately $100 \mathrm{mg}$ of the parent oxides were loaded into $\left(4 \times 8 \times 457.2 \mathrm{~mm}^{3}\right)$ stainless steel swagelock tube reactors (Charlotte Valve and Fittings, Inc.) and secured either by a $10 \mathrm{~mm}$ quartz glass frit (Technical Glass Products, Inc.) or by glass wool (Johns Manville, E-glass). The reactors were then placed inside a $30 \mathrm{~cm}$ tube furnace equipped with a multi-programmable controller (Barnstead/Thermolyne, Model F79345) and connected to a gas mixture supply. Subsequent back pressure tests were conducted to ensure that the reactant gas volumetric flow rate $\left(\sim 1 \mathrm{~m}^{3} / \mathrm{hr}\right)$ was not being inhibited. The process temperature was $\sim 950-1050^{\circ} \mathrm{C}$, whereas the startup temperature was $\sim 650-1050^{\circ} \mathrm{C}$. Each synthesis reaction began with a 5 to 10 minutes period for gas flow stabilization, which was followed by the initiation of the temperature ramping sequence. After completion of the temperature ramping program, the furnace was opened to allow rapid reactor cooling to room temperature under the reactant gas flow. Once room temperature was reached, the samples were passivated by slowly allowing air to diffuse through the reactor to the sample over a period of 24 hours. The passivation procedure was very important because transition-metal nitrides and carbides are extremely sensitive to air. Ultrasonic dispersion of interstitial transition-metal carbide materials is a convenient route for the large-scale synthesis of metallic nanoparticles. Porous Interstitial Compound Synthesis apparatus is shown in Fig 1. All materials were sonicated using the same procedure. Approximately 50 $\mathrm{mg}$ of the carbide material was placed in $50 \mathrm{ml}$ of 11.2 $\mathrm{M} \Omega$-cm deionized water to form solid-liquid slurry. The deionized water was prepared by a Corning Mega Pure
System using Barnstead Ultra-High Purity Disposable Deionizer Cartridges. As a preliminary step, the slurries were subjected to agitation for approximately 30 seconds using a variable speed touch mixer (Fisher Scientific, Model 232). The solid-liquid mixtures were then placed in a solid-state ultrasonic bath (L\&R Manufacturing, Model T-28B) and sonicated for 15-30 minutes. A portion of the ultrasonically dispersed solution was extracted (using a $30 \mathrm{ml}$ syringe) immediately following sonication and allowed to settle over a period of 96 to168 hours. After settling, the resulting liquid was extracted once more and the remaining solids were dried under vacuum at $398^{\circ} \mathrm{K}$ for 4 to 5 hours. In order to establish the structural characteristics of dispersed and undispersed carbide materials XRD, elemental analysis, and SEM were used to inspect the compound identity, composition, and particle surface morphology respectively.

\section{RESULTS AND DISCUSSIONS}

The temperature programmed reduction is a convenient technique for the characterization of supported metal oxide catalysts. Generally, TPR is used to provide the information on the influence of support materials, preparation and pretreatment procedures, and metal additives on catalyst reducibility. The directly observable quantities include the total consumption of the reducing agent and the temperatures of the reduction rate maxima26. A series of molybdenum carbides were prepared by the temperature programmed reduction/ carburization of $\mathrm{MoO}_{3}$ with equimolar mixtures of $\mathrm{CH}_{4} /$ $\mathrm{H}_{2}$ and $\mathrm{CO} / \mathrm{H}_{2}$. The materials resulting from $\mathrm{CH}_{4} / \mathrm{H}_{2}$ synthesis were identified through XRD as a hexagonal form of $\mathrm{Mo}_{2} \mathrm{C}$ that is in good agreement with $\alpha-\mathrm{Mo}_{2} \mathrm{C}$. Carbide materials produced with $\mathrm{CO} / \mathrm{H}_{2}$ agreed spar- 
ingly with few XRD PDF's and most closely resembles a form of $\mathrm{MoC}_{1-\mathrm{x}}$. The carbide materials $\left(\mathrm{MoC}_{5}, \mathrm{MoC}_{6}\right.$, and $\mathrm{MoC}_{8}$ ) prepared with a 1:1 ratio of $\mathrm{CH}_{4} / \mathrm{H}_{2}$ were similar upon the visual inspection of the products extracted after the reaction completion. These powders were composed of grayish-metallic crystallites. Contrary to these observations, the carbide powders synthesized using the $\mathrm{CO} / \mathrm{H}_{2}$ reaction gas mixture $\left(\mathrm{MoC}_{12}\right.$ and $\mathrm{MoC}_{16}$ ) displayed a copperish-brown metallic appearance and were composed of relatively larger coarse particles. The product was accessed by cutting the reactor open with a mechanical cutting lathe. During the sonication individualized waves were observed to move throughout the mixture. These actions were most visible by looking down into the solution as the jet waves could be seen impeding the opaque viscous layer. Immediately after sonication, the solution was noticed to continue a "swirling" action and was opaque and grayish-black in color. Over a period of several days of settling, the aqueous solution became clear and dark-blue as the nanoparticles settled out. The identity of the molybde-

(a

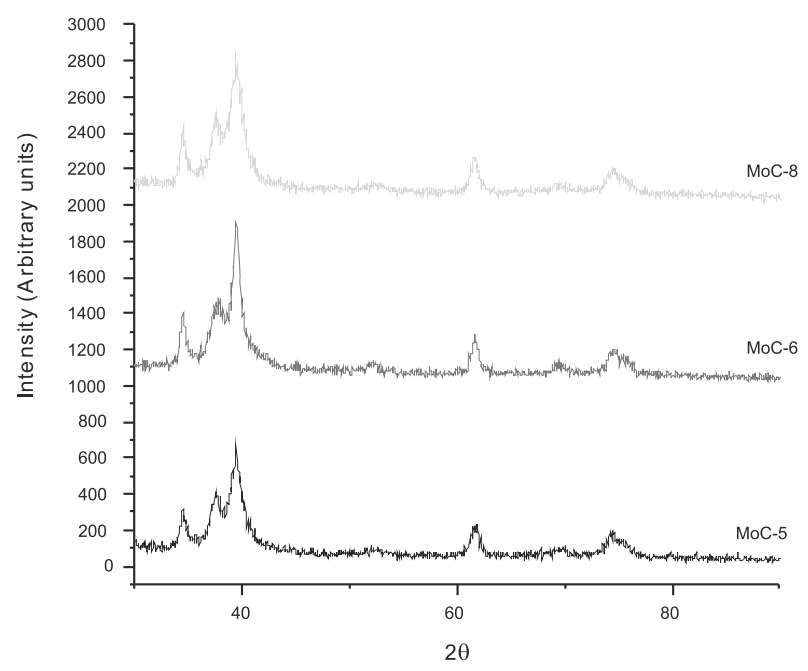

(b)

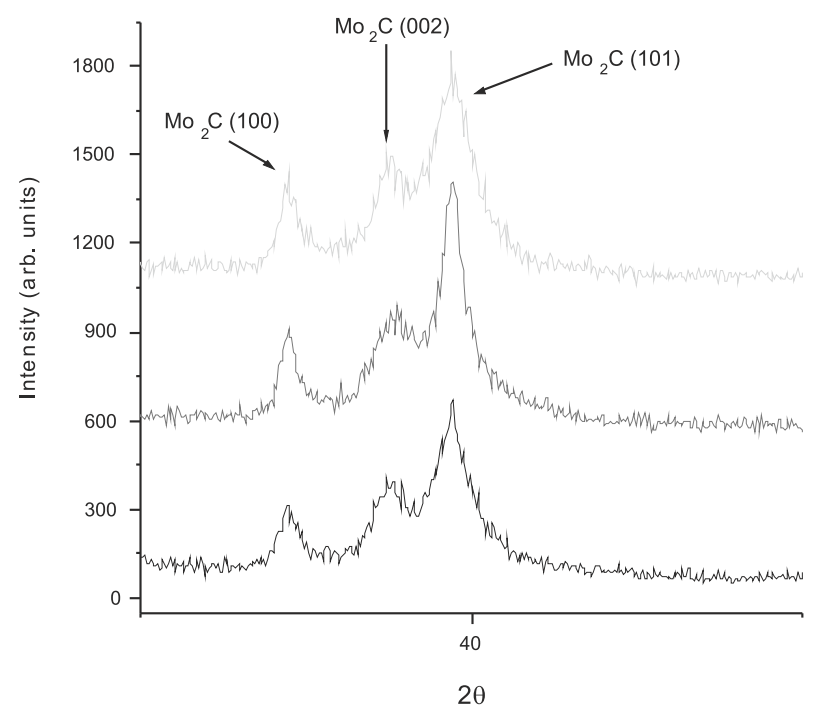

num carbide materials was confirmed using the RTXRD measurements. Average crystallite sizes were determined for the ultrasonically dispersed and non-dispersed molybdenum carbide materials. Using the SEM, elemental analysis was performed to identify the composition of the molybdenum carbide products. Lastly the surface morphology was studied using SEM.

The results of $\mathrm{MoC}_{5}, \mathrm{MoC}_{6}$, and $\mathrm{MoC}_{8}$ used $\mathrm{CH}_{4}$ as the carburization agent and produced essentially the same diffraction pattern when analyzed using RTXRD (Fig 2a, 2b). The only crystalline phase observed in this carbide group was $\mathrm{Mo}_{2} \mathrm{C}$. This observation was anticipated since according to the Mo-C phase diagram only hexagonal $\mathrm{Mo}_{2} \mathrm{C}$ is thermodynamically stable under the conditions employed in Rudy et al. ${ }^{27}$ These results are consistent with the XRD analysis conducted by Choi et al., ${ }^{4}$ and Oyama et al. ${ }^{28} \mathrm{X}$-ray reflections found at $39.4^{\circ}, 37.4^{\circ}$, and $34.4^{\circ}$ correspond to (101), (002), and (100) planes respectively. An average crystallite size is approximately $10.5 \mathrm{~nm}$ in the (101) direction, larger than $10 \mathrm{~nm}$ in the (002) direction and slightly smaller than $14 \mathrm{~nm}$ in the

(c)

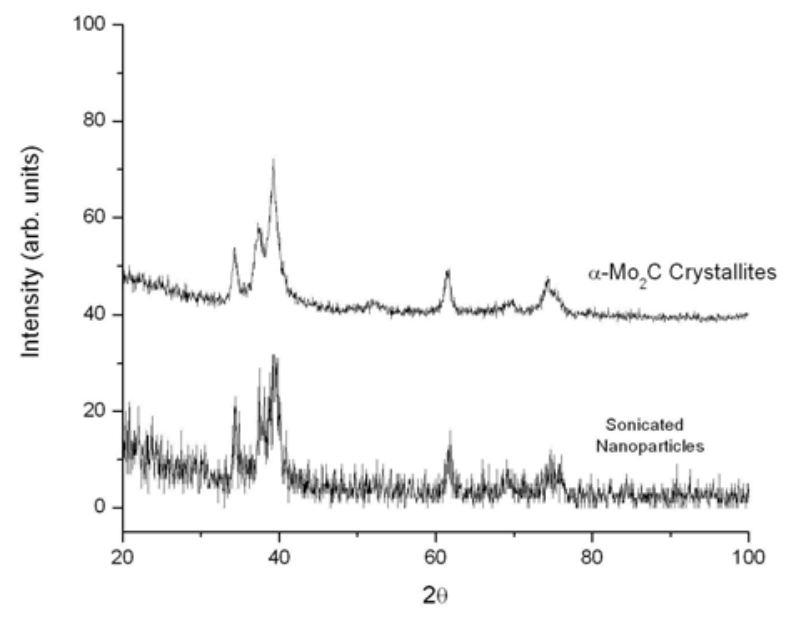

(d)

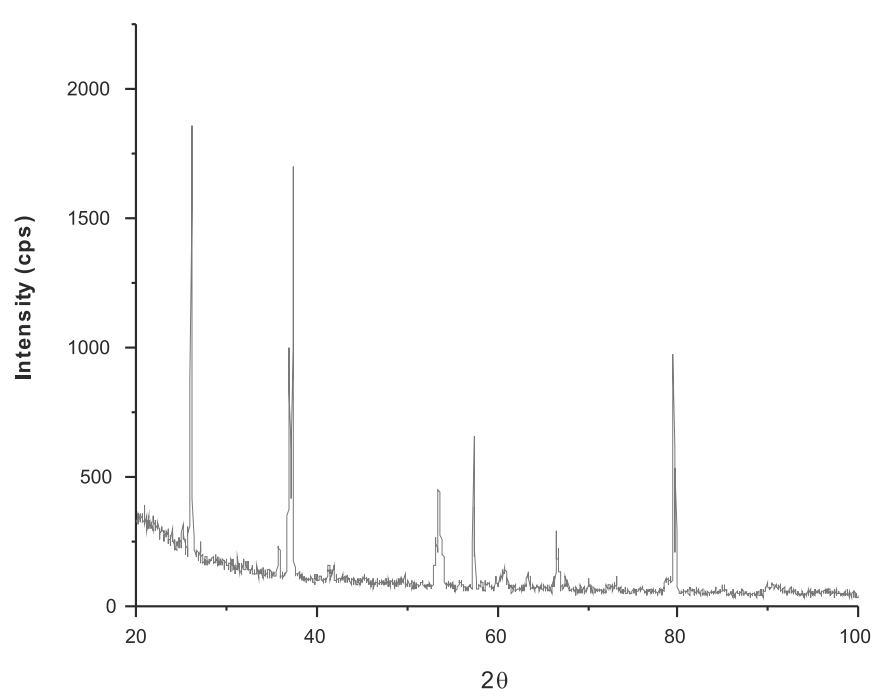

Figure 2. XRD analyses: (a) comparison of $\mathrm{Mo}_{2} \mathrm{C}$ X-ray diffraction patterns of the Methane Synthesis Group (b) relevant orientation planes of Hexagonal $\mathrm{Mo}_{2} \mathrm{C}$ (101), (002), and (100) directions shown (c) crystalline $\alpha-\mathrm{Mo}_{2} \mathrm{C}$ and $\mathrm{Mo}_{2} \mathrm{C}$ nanoparticles produced by ultrasonic irradiation of crystalline $\alpha-\mathrm{Mo}_{2} \mathrm{C}$ (d) pattern of $\mathrm{MoC1}_{3}$. (pattern mostly resembles a form of $\left.\mathrm{MoC}_{1-\mathrm{x}}\right)[\theta$ is in unit “o”(degree) $]$ 
(100) direction. Line broadening of the sonicated $\mathrm{Mo}_{2} \mathrm{C}$ reveals that the average crystallite size extends in the (101) direction to slightly more than $11 \mathrm{~nm}$ and less than 15 $\mathrm{nm}$ in the (100) direction. Comparison of the sonicated $\mathrm{Mo}_{2} \mathrm{C}$ with the undispersed $\mathrm{Mo}_{2} \mathrm{C}$ shows that the bulk phase remains that of $\mathrm{Mo}_{2} \mathrm{C}$ ( $\mathrm{Fig} 2 \mathrm{c}$ ). The results of $\mathrm{MoC}_{13}$ and $\mathrm{MoC}_{16}$ used $\mathrm{CO}$ as the carburization agent and produced essentially the same diffraction pattern when analyzed using the RTXRD. The diffraction pattern of $\mathrm{MoC}_{13}$ was analyzed with a scan speed equal to 1 . In this case, increasing the scan speed gave the pattern greater distinction during peak identification. The XRD pattern of $\mathrm{MoC}_{13}$ is given in Fig 2d. The most intense peaks occur at $25.5^{\circ}$ and $38.1^{\circ}$. Matching this pattern to a specific material was relatively difficult because there was not any one distinguishable PDF that corresponded in great detail with $\mathrm{MoC}_{13}$. Although the most intense do not match any of the files, a few of the secondary peaks match up with a form of $\mathrm{MoC}_{1-\mathrm{x}}$. Possible reasons for this occurrence are given in the discussion section. Using the most intense peak, the average crystallite size was determined to be approximately $43 \mathrm{~nm}$. The results of scanning electron microscopy on the molybdenum carbon compounds reveal several different characteristics. SEM analysis of the $\mathrm{Mo}_{2} \mathrm{C}$ was taken at a range interval from 10 microns to $100 \mathrm{~nm}$ at magnifications varying from 1000 to 40000 . As shown in Fig 3a, the undispersed at $10 \mu \mathrm{m}$ and 5000 magnifications, displays a collection of platlets or flake structures, which may be analogous to small "playing cards" on the right hand side. Small resemblances of macro crystals at the top middle and needle-like crystals along the bottom left side. Fig $3 b$ shows dispersed $\mathrm{Mo}_{2} \mathrm{C}$ where there is an absence of macrocrystals. Flake and needle-like particles appear to be more dispersed; in addition, layered thin crystals are present in the upper left corner. There exists some speculation that preparing $\mathrm{Mo}_{2} \mathrm{C}$ using the TPR method may yield intermediate compounds, such as molybdenum oxycarbide $\left(\mathrm{MoO}_{\mathrm{x}} \mathrm{C}_{1-\mathrm{x}}\right)$. The XRD analyses performed in this study confirmed that Mo2C were produced and that there was no evidence of the oxy-carbide compounds.

A series of tungsten carbides (WC) was prepared by the temperature programmed reduction/carburization of $\mathrm{WO}_{3}$ with equimolar mixtures of $\mathrm{CH}_{4} / \mathrm{H}_{2}$. XRD analyses reveal that hexagonal WC was produced. Other trials of tungsten carbide synthesis produced a form most notably corresponding to $\mathrm{WC}_{\mathrm{x}}$. Carbide materials $\left(\mathrm{WC}_{9}, \mathrm{WC}_{10}\right.$, $\mathrm{WC}_{17}$ ) prepared with a 1:1 ratio of $\mathrm{CH}_{4} / \mathrm{H}_{2}$ yielded differ- ent results upon visual inspection of the products. $\mathrm{WC}_{9}$ powders were comprised of grayish-metallic grains similar to those of $\mathrm{Mo}_{2} \mathrm{C}$ and $\mathrm{Mo}_{2} \mathrm{~N}$. WC10 powders were brown, while $\mathrm{WC}_{11}$ and $\mathrm{WC}_{17}$ yielded dark-purple powders. The only noticeable difference in the preparation of these materials was the change in temperature ramping rates $\Delta_{1}$ and $\Delta_{2}$. These values are shown in Table 1. All WC products were obtained by cutting the reactors open in a similar fashion as that of $\mathrm{MoC}_{8}$. Preparation of tungsten carbide nanoparticles was completed using $\mathrm{WC}_{9}$. Upon the addition of deionized water to the tungsten carbide,

(a)

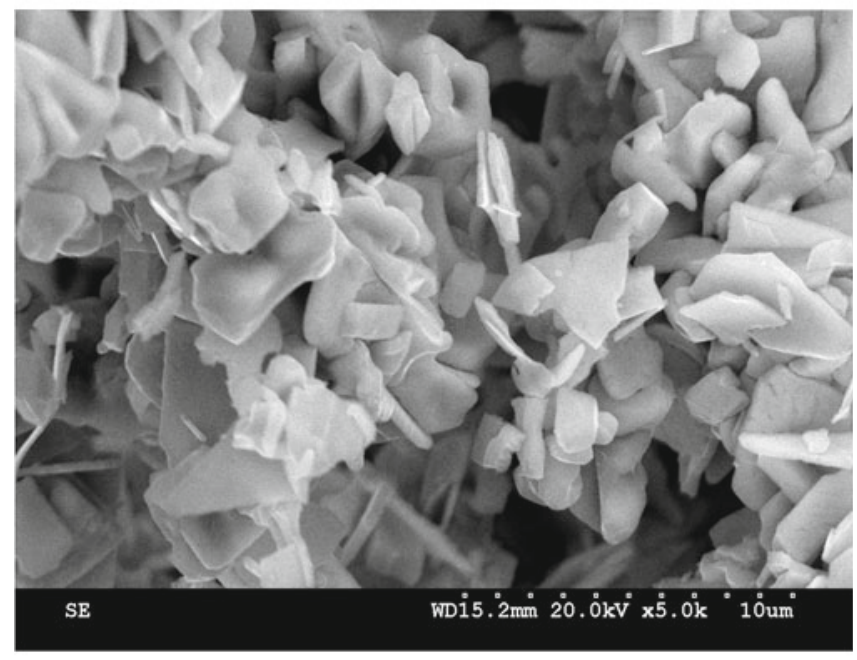

(b)

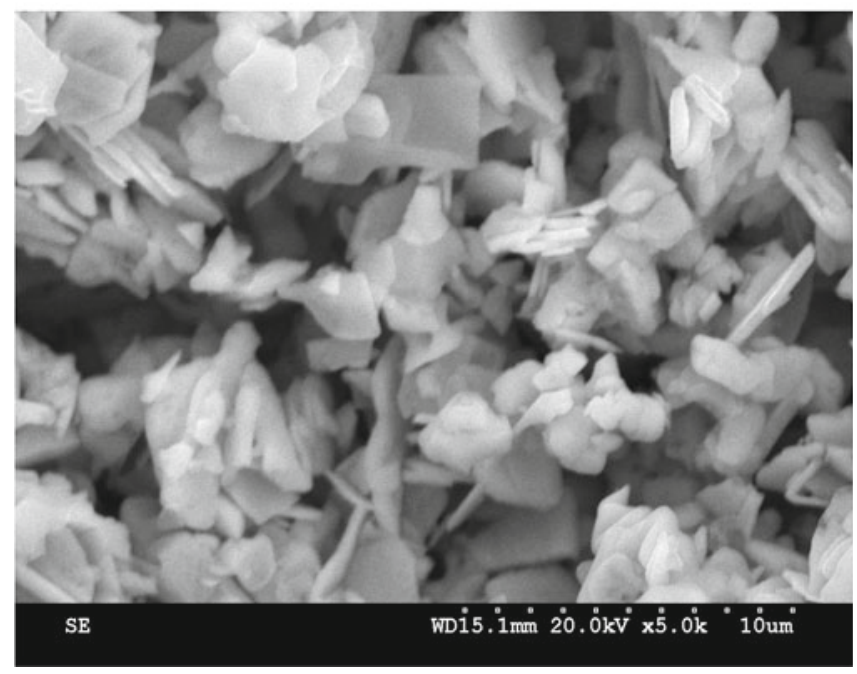

Figure 3. SEM micrograph: (a) undispersed $\alpha-\mathrm{Mo}_{2} \mathrm{C}$ (b) dispersed $\alpha-\mathrm{Mo}_{2} \mathrm{C}$

Table 1. Change in temperature ramping rate $(\Delta-$ temperature ramping rate, $\mathrm{K}-\mathrm{Kelvin}, \mathrm{h}-$ hour, MSHV - mass hourly space velocity)

\begin{tabular}{|l|c|c|c|c|}
\hline $\begin{array}{l}\text { Product } \\
\text { Code }\end{array}$ & $\begin{array}{c}\Delta \\
1 \\
(\mathrm{~K} / \mathrm{h}\end{array}$ & $\begin{array}{c}\Delta \\
2 \\
(\mathrm{~K} / \mathrm{h})\end{array}$ & $\begin{array}{c}\text { MHSV } \\
(1 / \mathrm{h})\end{array}$ & $\begin{array}{c}\text { Final Temperature } \\
(\mathrm{K})\end{array}$ \\
\hline $\mathrm{MoC}_{5}$ & 27 & 60 & 30 & 1093 \\
\hline $\mathrm{MoC}_{6}$ & 27 & 60 & 30 & 1093 \\
\hline $\mathrm{MoC}_{8}$ & 27 & 120 & 30 & 1093 \\
\hline $\mathrm{MoC}_{12}$ & 27 & 120 & 45 & 1093 \\
\hline $\mathrm{MoC}_{16}$ & 27 & 120 & 45 & 1093 \\
\hline $\mathrm{WC}_{9}$ & 10.75 & 120 & 30 & 1148 \\
\hline $\mathrm{WC}_{10}$ & 21.5 & 120 & 30 & 1148 \\
\hline $\mathrm{WC}_{17}$ & 21.5 & 180 & 30 & 1148 \\
\hline
\end{tabular}


the solution turned dark gray and an opaque charcoal layer formed above the aqueous solution, a result similar to that of $\mathrm{Mo}_{2} \mathrm{C}$. As with the $\mathrm{Mo}_{2} \mathrm{C}$ solid-liquid mixture, only rigorous agitation using a touch mixer dispelled the charcoal-like layer into the solution. Additionally the "jet waves" described during $\mathrm{Mo}_{2} \mathrm{C}$ sonication were also observed during the WC dispersion. During the settling period, the solution became clear and light gray in color. RTXRD was used in order to confirm the identity of $\mathrm{WC}_{9}$ as hexagonal carbide. The identity of $\mathrm{WC}_{10}, \mathrm{WC}_{11}$, and $\mathrm{WC}_{17}$ most closely corresponds to a form of $\mathrm{WC}_{1-\mathrm{x}}$. Fig. 4 a displays the collected XRD pattern for $\mathrm{WC}_{9}$. As shown, the most intense peaks occur at diffraction angles $2 \theta=35.6^{\circ}, 48.2^{\circ}$, and $31.5^{\circ}$. These peaks correspond with the (100), (101), and (001) orientation planes respectively. Computed average grain size yields approximately 9.6 and $9.7 \mathrm{~nm}$ in the (100) and (101) directions respectively. Although the crystallite sizes reported in this work are approximately half of those measured by Oyama et al. ${ }^{5}$ the XRD pattern of $\mathrm{WC}_{9}$ strongly agrees with Oyama's ${ }^{1}$ study. X-ray diffraction was used to analyze the ultrasonically dispersed WC product. Comparison of the WC nanoparticles and the hexagonal-WC material show that

(a)

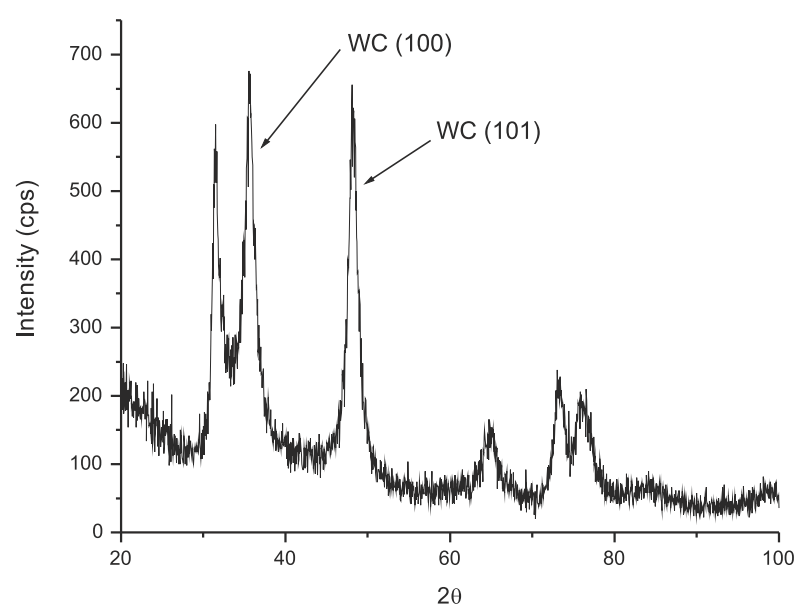

(b)

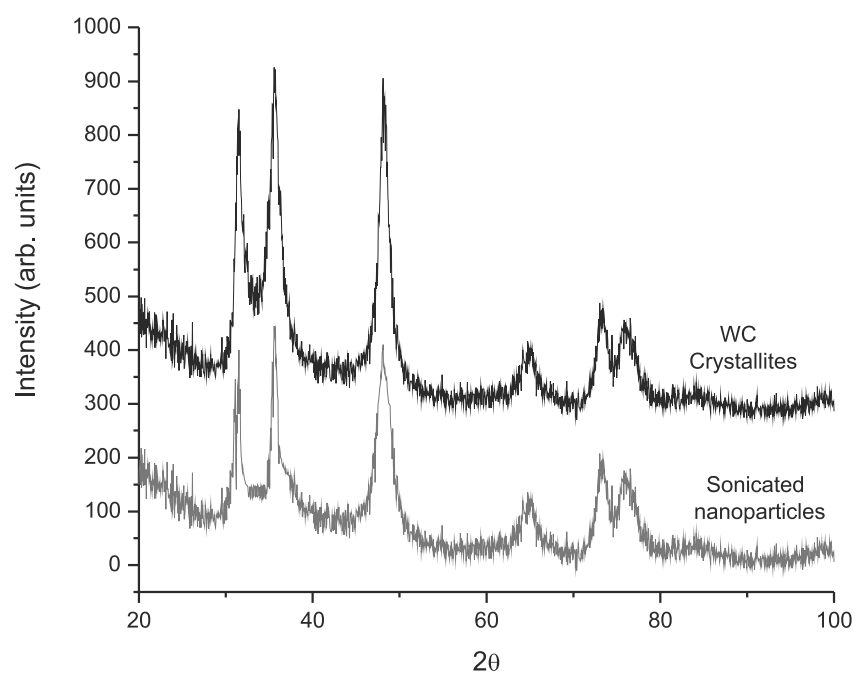

Figure 4. XRD analyses: (a) patterns of WC produced by TPR of $\mathrm{WO}_{3}$ and $\mathrm{CH}_{4} / \mathrm{H}_{2}$ reactant gas mixture (b) hexagonal WC and WC nanoparticles created by ultrasonic dispersion [ $\theta$ is in unit "o"(degree)]
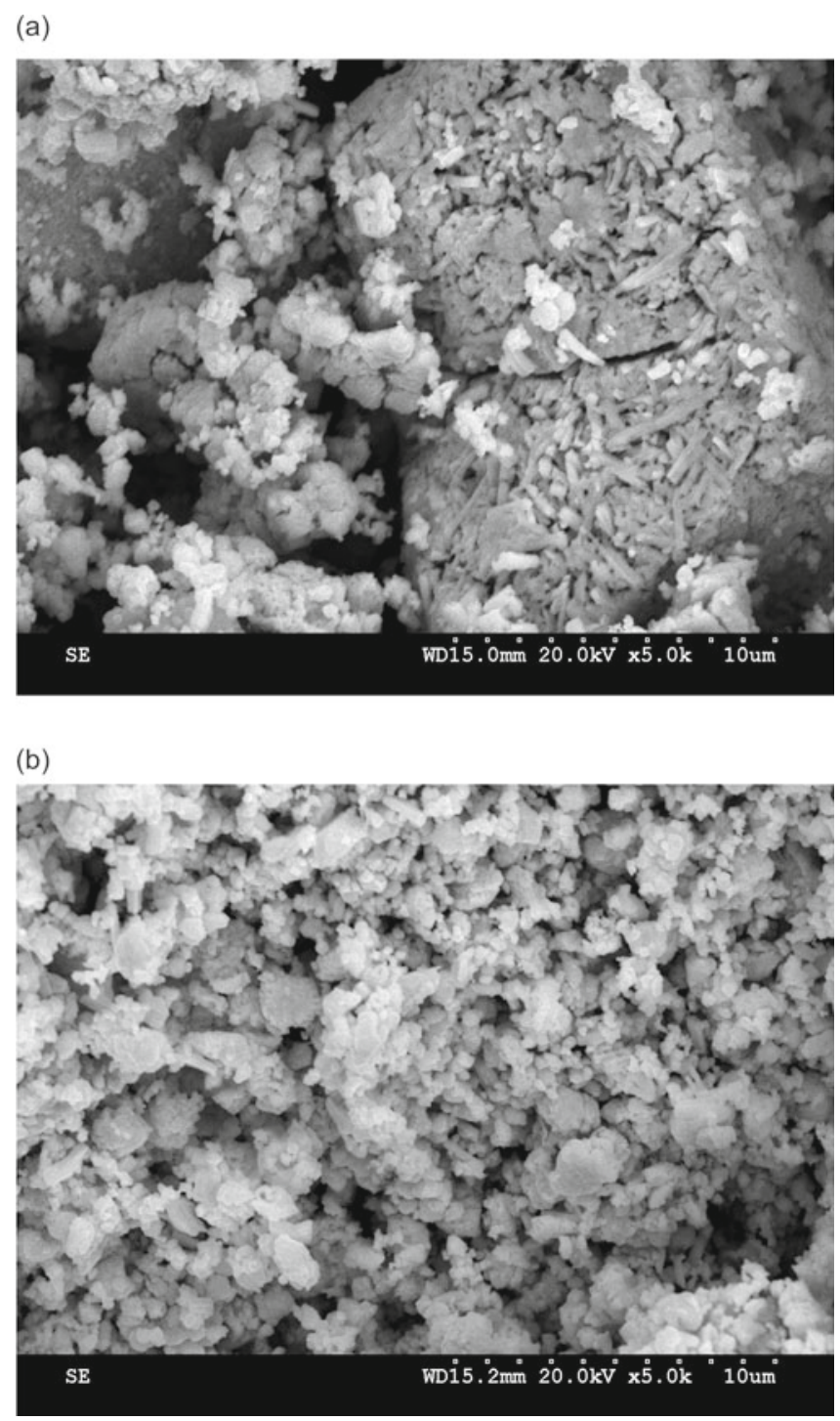

Figure 5. SEM analyses: (a) undispersed WC (b) ultrasonically dispersed WC

only peaks due to WC was observed (Fig. 4b). Scherrer analysis of the peak widths indicates little change in the size of the crystalline domains: the nanoparticles extend slightly to $10.2 \mathrm{~nm}$ in the (100) direction and $10 \mathrm{~nm}$ in the (101) direction.

The SEM analyses of the tungsten carbide products show a variety of different morphologies. Fig 5a shows non-sonicated $\mathrm{WC}_{\mathrm{x}}$ at $10 \mu \mathrm{m}$ and 5000 magnifications. The micrograph shows a variety of fine needle like crystals, randomly directed but uniformly dispersed. Some crystals display a layered thin-flake appearance representative of high crystality. The ultrasonic irradiation effects are observed in great detail using SEM analysis of WC. Fig 5b shows undispersed WC as large macrocrystals surrounded by various spherical shaped particles.

\section{KINETIC SYNTHESIS MODELS FOR MO2C AND WC}

The kinetic diffusion model for the diffusion of oxygen and carbon was studied using the diffusion model proposed by Kapoor and Oyama ${ }^{29}$. The mathematical calculations were also performed to transpire what is happening in the reduction of molybdenum and tungsten oxide with $\mathrm{CO}_{2} / \mathrm{CH}_{4}$ to produce molybdenum and tungsten carbide respectively. Oyama et al., ${ }^{\mathbf{2 8}}$ have previously studied the diffusivities of oxygen and nitrogen 
in the $\mathrm{V}_{2} \mathrm{O}_{5}$. Kapoor and Oyama ${ }^{29}$ studied the diffusion coefficients of oxygen and nitrogen through the temperature programmed reactions. The same model was extended in determining the diffusivities of oxygen and carbon in oxide to carbide.

Diffusivity is determined by matching an observable experimental quantity, namely the peak temperature of the species diffusing out of the solid to a Fickian diffusion model for the process. Kapoor and Oyama ${ }^{22}$ assumed that one-dimensional diffusion was occurring in a semi-infinite slab, which meant the activated diffusion process could be applied by Fick's second law of diffusion equation. This expression is as follows:

(a)
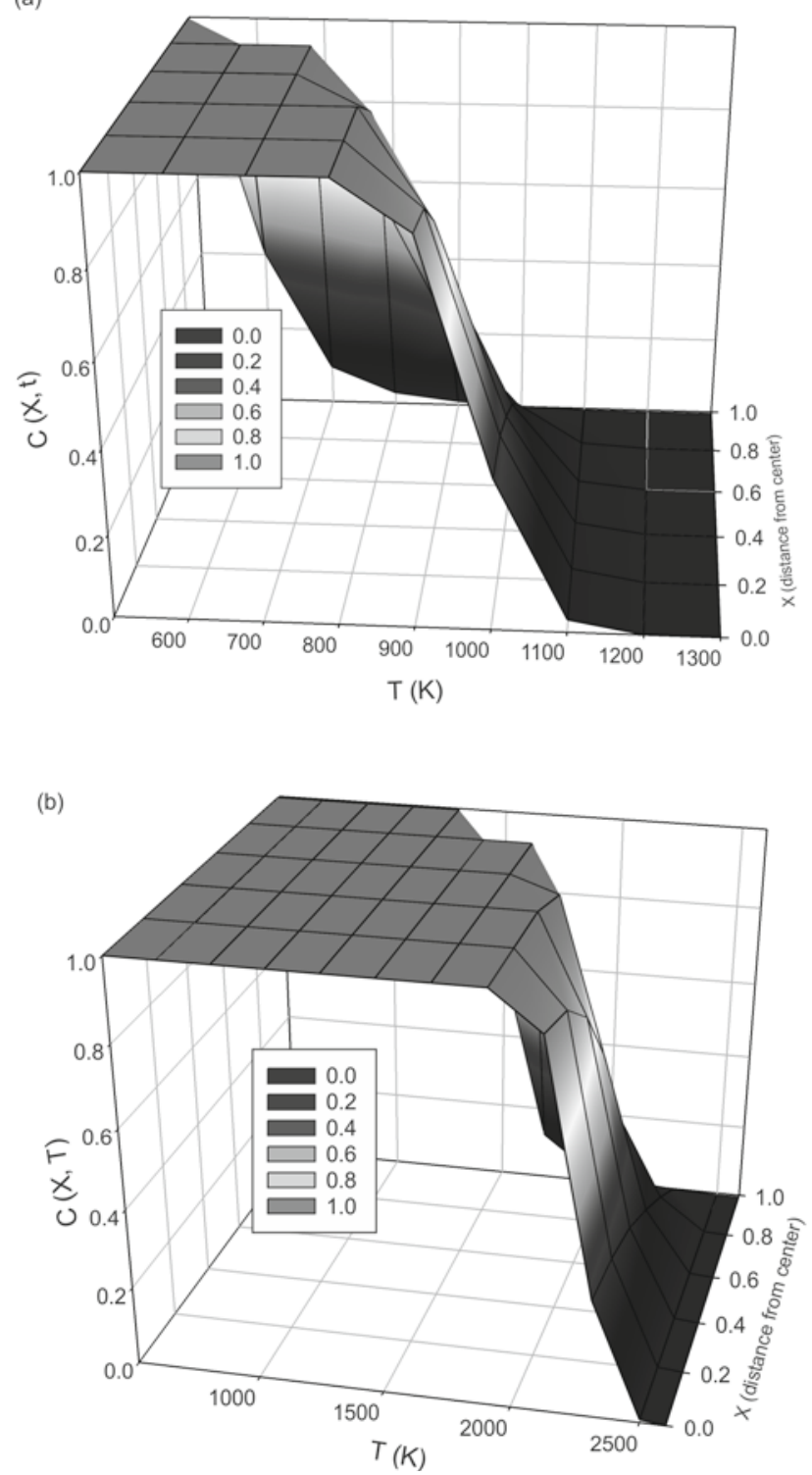

Figure 6. Surface plot of concentration profiles within the slab: (a) $\mathrm{Mo}_{2} \mathrm{C}$ (b) $\mathrm{WC}$ $\frac{\partial C}{\partial t}=\frac{D_{o}}{h^{2}} \exp \left(-\frac{E}{R T}\right) \frac{\partial^{2} C}{\partial X^{2}}$

Where $C$ is the ratio of concentration at any time to the initial concentration, $C=c / c_{0}$, and $X$ is the ratio of the distance from the center of the slab to its halfthickness, $X=x / h$. Then by inserting the temperature dependence $\left(T=T_{o}+\beta_{t}\right)$ into Eq. 2, and applying boundary conditions final concentration profile (Eq. 2) and diffusion rate (Eq. 3 ) is determined.

$C(X, t)=\sum_{n=1}^{\infty} \frac{2(-1)^{n-1}}{\lambda_{n}} \exp \left(\frac{\lambda_{n}^{2} \tau}{h^{2}}\right) \cos \left(\lambda_{n} X\right)$

$r_{t}=\frac{2 D}{h^{2}} \sum_{n=1}^{\infty} \exp \left(-\frac{\lambda_{n}^{2} \tau}{h^{2}}\right)$

Here $\lambda_{n}$ are eigenvalues $(2 n-1) \pi / 2$. These are calculated using Sturn-Liouville equation, for $\mathrm{n}=1,2,3, \ldots \ldots \ldots \ldots$, and $\tau=\int D d t=\int D_{o} \exp ^{[-E R T]}$. E was calculated from the Redhead equation ${ }^{30}$.

The parameters which were used in this study are listed in Table 2. In-situ HTXRD experimental data and solid state kinetic models indicate that the thermal activation of oxygen diffusion takes place at lower temperatures approximately $500 \mathrm{~K}$ than nitrogen infusion at $1250 \mathrm{~K}$ into the molybdenum lattice structure. For the case of tungsten lattice structure oxygen diffuses at $1400 \mathrm{~K}$ and nitrogen infuses at $2600 \mathrm{~K}$. Concentrations profile is shown in Fig 6. Both activation temperatures strongly correspond to experimental observations and theoretical predictions. Dissociated hydrogen appears to act not only as a chemical trap for escaping oxygen atoms but also as a reactive species for the formation of possible molybdenum bronze materials between 400 to $1300 \mathrm{~K}$ and for tungsten materials between 1300 to 2600 $\mathrm{K}$. Precision of the established model in this study was in our experimental data uncertainty ( $\sim 2 \%$ deviation). However, the results could not be validated further by any other literature values because no investigation was found so far in this maneuver.

\section{CONCLUSION}

Temperature Programmed Reaction (TPR) and ultrasonic irradiation provided an effective pathway to synthesize transition-metal carbide nanoparticles. Polycrystalline $\alpha-\mathrm{Mo}_{2} \mathrm{C}$ was synthesized from $\mathrm{MoO}_{3}$ macrocrystals by TPR in $\mathrm{CH}_{4} / \mathrm{H}_{2}$ gases. The $\alpha-\mathrm{Mo}_{2} \mathrm{C}$ crystallites were relatively small and dark metallic-gray in color. Slight changes in temperature ramping rate did not change the structure of the resulting $\alpha-\mathrm{Mo}_{2} \mathrm{C}$. A form of molybdenum carbide that closely resembled $\mathrm{MoC}_{1-\mathrm{x}}$ was produced by TPR in $\mathrm{CO} / \mathrm{H}_{2}$. The $\mathrm{MoC}_{1-\mathrm{x}}$ material appeared to have relatively larger and coarser grains than $\alpha-\mathrm{Mo}_{2} \mathrm{C}$. Hexagonal WC was prepared by TPR in a $\mathrm{CH}_{4} / \mathrm{H}_{2}$ reactant gas mixture. Unlike $\alpha-\mathrm{Mo}_{2} \mathrm{C}$ synthesis

Table 2. List of parameters used in Kinetic model

\begin{tabular}{|l|c|c|c|}
\hline parameters & Mo & W & unit \\
\hline$D_{\circ}$ (diffusivity coefficient) & 0.000013 & 0.00000085 & $\mathrm{~m}^{2} / \mathrm{s}$ \\
$h$ (particle size) & 14 & 10 & $\mathrm{~nm}$ \\
$E$ (activation energy) & 101000 & 260000 & $\mathrm{~J} / \mathrm{mol}$ \\
$\beta$ (temperature coefficient) & 0.083 & 0.083 & $\mathrm{~K} / \mathrm{s}$ \\
$T_{0}$ (reference temperature) & 298.15 & 298.15 & $\mathrm{~K}$ \\
$R$ (gas constant) & 8.314 & 8.314 & $\mathrm{~J} / \mathrm{mol} / \mathrm{K}$ \\
\hline
\end{tabular}


the WC products were affected by slight changes in the temperature ramping program. WC was obtained using $\Delta_{1}$ $=11 \mathrm{~K} / \mathrm{h}^{-0.5}$ and $\Delta_{2}=120 \mathrm{~K} / \mathrm{h}$, and was metallic-gray in color. In addition to hexagonal WC, a form of tungsten carbide that strongly agreed with XRD patterns of $\mathrm{WC}_{\mathrm{x}}$ was also produced. Ultrasonic irradiation provided a convenient route to produce nanoparticles from refractory carbide powders. XRD analyses displayed that $\alpha-\mathrm{Mo}_{2} \mathrm{C}$ crystallite size was $10-14 \mathrm{~nm}$, while the ultrasonically dispersed $\alpha-\mathrm{Mo}_{2} \mathrm{C}$ nanoparticles extended to $10.5-15$ $\mathrm{nm}$. WC had an average crystallite size of 9-14 nm and extended slightly to $10-14$ in the nanoparticles. This work has determined that TPR synthesis of topotactic molybdenum and tungsten carbide powders followed by ultrasonic irradiation can produce transition-metal carbide nanoparticles.

\section{LITERATURE CITED}

1. Oyama, T., (1996). "The chemistry of transition metal carbides and nitrides," London, Chapman and Hall.

2. Storms, E.K., (1967). The Refractory Carbides, Academic Press, New York.

3. Toth, L.E., (1971). Transition Metal Carbides and Nitrides, Academic Press, New York.

4. Choi, J., Brenner, J. \& Thompson, L.. (1995). Pyridine Hydroenitrogenation Over Molybdenum Carbide Catalysts, Journal of Catalysis, 154, 33-40. DOI:10.1006/jcat.1995.1143.

5. Oyama, S.T., Schlatter, J.C., Metclafe, J.E. \& Lambert, J.M., (1988). Preparation and Characterization of Early Transition-Metal Carbides and Nitrides, Ind. Eng. Chem. Res., 27, 1639-1648. DOI: 10.1021/ie00081a013.

6. Gu, Y., Li, L., Chen, Z., Yang, Y. \& Qian, Y., (2003). Synthesis of nanocrystalline $\mathrm{Mo}_{2} \mathrm{C}$ via sodium co-reduction of MoCl5 and CBr4 in Benzene, Mater. Res. Bull., 38, 1119-1122. DOI:10.1016/S0025-5408(03)00132-6.

7. Hyeon, T., Fang, M. \& Suslick, K., (1996). Nanostructured Molybdenum Carbide: Sonochemical Synthesis and Catalytic Properties, J. Am. Chem. Soc., 118, 5492-5493. DOI: 10.1021/ ja9538187.

8. Mcgee, R., Bej, S. \& Thompson, L., (2005). Basic properties of molybdenum and tungsten nitride catalysts, Appl. Catal. A., 284, 139-146. DOI:10.1016/j.apcata.2005.01.029.

9. Weimer, A. (1997). Carbide, Nitride and Boride Materials Synthesis and Processing, New York, Chapman and Hall.

10. Giordano, C., Erpen, C., Yao, W. \& Antoniettin, M., (2008). Synthesis of Mo and W Carbide and Nitride Nanoparticles via a Simple "Urea Glass" Route, Nano Lett., 8, 4659-4663. DOI: 10.1021/nl8018593.

11. Patel, M. \& Subrahmanyam, J., (2008). Synthesis of nanocrystalline molybdenum carbide $\left(\mathrm{Mo}_{2} \mathrm{C}\right)$ by solution route, Mater. Res. Bull., 43, 2036-2041. DOI:10.1016/j.materresbull.2007.09.025.

12. Keller, N., Pietruszka, B. \& Keller, V.. (2006). A new one-dimensional tungsten carbide nanostructured material, Mater. Lett., 60, 1774-1777. DOI:10.1016/j.matlet.2005.12.017.

13. Singh, R.P., (2008). Synthesis and characterization of tungsten carbide nanoparticles. School of Physics \& Materials Science, MS Thesis., Thapar University, Patiala.

14. Yamada, K., (2000). Synthesis of tungsten carbide by dynamic shock compression of a tungsten-acetylene black powder mixture, J. Alloy Compd., 305, 253-258. DOI:10.1016/ S0925-8388(00)00700-3.

15. Kurishita, H., Matsuso, S., Arakawa, H., Hirai, T., Linke, J., Kawai, M. \& Yoshida, N. (2009). Development of nanostructured W and Mo materials, Adv. Mater. Res., 59, 18-30. DOI: 10.4028/www.scientific.net/AMR.59.18.

16. de Medeiros, F.F.P., da Silva, A.G.P., de Souza, C.P. \&
Gomes, U.U., (2009). Carburization of Ammonium Paratungstate by Methane: The influence of Reaction Parameters, Int. J. Refract. Metals and Hard Materials., 27, 43-47. DOI:10.1016/j. ijrmhm.2008.03.001.

17. Reddy, K.M., Rao, T.N., Radha, K. \& Joardan, J. (2010). Nanostructured Tungsten Carbides by Thermochemical Processing, J. Alloys and Compounds., 494, 404-409. DOI:10.1016/j. jallcom.2010.01.059.

18. Cetinkaya, S. \& Eroglu, S. (2011). Comparative Kinetic $\&$ Structural Analysis of Nanocrystalline WC Powder Synthesis from Pre-reduced W under Pure and Diluted $\mathrm{CH}_{4}$ Atmospheres, Int. J. Refract. Metals and Hard Materials., 29, 214-220. DOI:10.1016/j.ijrmhm.2010.10.009.

19. Oyama, S.T. (1981). "Ammonia synthesis and decomposition on molybdenum and its interstitial alloys." PhD Dissertation, Stanford University, Stanford, CA.

20. Kanervo, J. (2003). "Kinetic analysis of temperature programmed reactions." PhD Dissertation, Helsinki University of Technology.

21. Knotzinger, H. (1997). "Temperature-programmed reduction, In Handbook of Heterogeneous Catalysis,” Eds. Etrl, G., Knozinger, H., Weitkamp, J., Vol 2, VCH, Weinheim, pp 676.

22. Bhatia, S., Beltramini, I. \& Do, D.D. (1990). "Temperature-programmed analysis and its applications in catalytic systems." Catal. Today, 7, 309-438.

23. Jones, A. \& McNicol, B. (1986). "Temperature-programmed reduction for solid materials characterization." Marcel Dekker Inc., New York.

24. Lemaitre, J.L. (1984). "Temperature-programmed methods, in characterization of heterogeneous catalysts." Ed. Delannay, F., Marcel Dekker, Inc., New York, pp 29-70.

25. Hurst, N.M., Gentry, S.J. \& Jones, A. (1982). “Temperature - programmed desorption and reduction." Catal. Rev. -Sci. Eng., 24, 233-309.

26. Kanervo, J.M. \& Krause, A.O.I. (2001) "Kinetic Analysis of temperature programmed reduction: behavior of a $\mathrm{CrO}_{\mathrm{x}} /$ $\mathrm{Al}_{2} \mathrm{O}_{3}$ Catalyst." J. Phys. Chem. B, 105, 9778-9784.

27. Rudy, E., Windish, S., Stosick, A. \& Hoffman, J. (1967). Revision of the Titanium-Tungsten System, Trans TMS-AIME., 239, 1247-1267.

28. Oyama, S.T., Schlatter, J., Metcalfe, J. \& Lambert, J. (1988). Preparation and characterization of early transition metal carbides and nitrides, Ind. Eng. Chem. Res., 27, 1639-1648. DOI: 10.1021/ie00081a013.

29. Kapoor, R. \& Oyama, S.T. (1997). Measurement of solid state diffusion coefficients by a temperature-programmed method, J. Mater. Res., 12, 467-473. DOI: 10.1557/JMR.1997.0068.

30. Redhead, P.A., (1962). Thermal Desorption of Gases, Vacuum., 12, 203-211. DOI:10.1016/0042-207X(62)90978-8. 